PIVETTA, L. G.; ZANOTTO, M. D.; TOMAZ, C. A.; PIVETTA, L. A.; FIOREZE, A. C. L.; ZOZ, T. Avaliação de genótipos de mamona em diferentes níveis de adubação. Revista de Agricultura Neotropical, Cassilândia-MS, v. 2, n. 2, p. 9-18, abr./jun. 2015.

\title{
AVALIAÇÃO DE GENÓTIPOS DE MAMONA EM DIFERENTES NÍVEIS DE ADUBAÇÃO
}

\section{LAERTE GUSTAVO PIVETTA ${ }^{1}$, MAURÍCIO DUTRA ZANOTTO ${ }^{2}$, CAMILA DE AQUINO TOMAZ ${ }^{2}$, LAÉRCIO AUGUSTO PIVETTA ${ }^{3}$, ANA CAROLINA DA COSTA LARA FIOREZE ${ }^{4}$, TIAGO ZOZ}

\begin{abstract}
1 Instituto Federal de Educação, Ciência e Tecnologia de Mato Grosso (IFMT), Sorriso/MT, Brasil, laerte.pivetta@srs.ifmt.edu.br; ${ }^{2}$ Universidade Estadual Paulista "Júlio de Mesquita Filho" (UNESP), Faculdade de Ciências Agronômicas, Botucatu/SP, Brasil, zanotto@fca.unesp.br, caatomaz@hotmail.com; ${ }^{3}$ Universidade Federal do Paraná (UFPR), Palotina/PR, Brasil, laerciopivetta@ufpr.br; ${ }^{4}$ Universidade Federal de Santa Catarina (UFSC), Curitibanos/SC, Brasil, ana.lara@ufsc.br; ${ }^{5}$ Universidade Estadual de Mato Grosso do Sul (UEMS), Cassilândia-MS, Brasil, zoz@uems.br
\end{abstract}

RESUMO: O estudo teve como objetivo avaliar a resposta de híbridos do Programa de Melhoramento de Mamona da UNESP/FCA e de cultivares de mamona em diferentes níveis de adubação. O delineamento experimental utilizado foi de blocos ao acaso, em esquema fatorial 4x4, com quatro repetições. O primeiro fator correspondeu aos quatro genótipos de mamona [dois híbridos (A e B) e duas cultivares (FCA-PB e IAC 2028)] e o segundo fator correspondeu aos quatro níveis de adubação $(0,50,100$ e $150 \%$ da dose recomendada com base na análise de solo). A cultivar IAC 2028 apresentou o menor número de racemos, mas obteve maior número de grãos por racemo, massa de 100 grãos e produtividade. $\mathrm{O}$ aumento da dose de adubo aumentou todos os componentes de produção e a produtividade da mamona. Conclui-se que adubação acima da recomendada promove aumento da produtividade e lucratividade da mamona.

PALAVRAS-CHAVE: Híbridos, cultivares, colheita mecanizada.

\section{EVALUATION OF CASTOR BEAN GENOTYPES SUBMITTED TO DIFFERENT FERTILIZATION LEVELS}

\begin{abstract}
A study was conducted to evaluate the response of the castor bean hybrids of UNESP/FCA Breeding Program and commercial cultivars submitted to different fertilization levels. The experimental was arranged in a randomized blocks design, in a $4 \times 4$ factorial, composed of four castor bean genotypes [two hybrids (A and B) and two cultivars (FCA-PB and IAC 2028)] and four fertilization levels $(0,50,100$ and $150 \%$ of the recommended rate based on soil analysis). The IAC 2028 cultivar had the lower number of racemes per plant, but had the highest number of grains per raceme, mass of 100 grains and grain yield. The increase in fertilization levels increased all the yield components and the grain yield. The results suggest that fertilizer application above the recommended rate promotes increased grain yield and higher profits in the production of castor beans.
\end{abstract}

KEYWORDS: Hybrids. cultivars. mechanical harvesting.

\section{INTRODUÇÃO}

A produção nacional de mamona na safra 2013/2014, segundo os levantamentos da Companhia Nacional de Abastecimento foi de 44,7 mil toneladas, com uma produtividade 
média de $441 \mathrm{~kg} \mathrm{ha}^{-1}$ (CONAB, 2015a). O Brasil, que já foi o maior produtor mundial da mamona em baga no período de 1960-1980, atualmente é apenas o quarto maior produtor de grãos de mamona, com 1,3\% da produção mundial (FAO, 2014).

O principal produto da mamona é o óleo presente em seus grãos, que possui inúmeras aplicações, incluindo o uso medicinal e cosmético, fabricação de plásticos e lubrificantes. $\mathrm{O}$ óleo também é utilizado na produção de fibra ótica, vidro à prova de balas e próteses ósseas, além disso, é indispensável para impedir o congelamento de combustíveis e lubrificantes de aviões e foguetes espaciais a baixíssimas temperaturas (CHIERICE; CLARO NETO, 2007).

Apesar da vasta utilidade industrial e do potencial de cultivo no Brasil a produção está muito aquém da demanda nacional. As formas de promover aumento da produção são o aumento da área e o aumento da produtividade. A área de cultivo de mamona pode ser incrementada com a possibilidade de expansão na Região Centro-Oeste. Em análise sobre a perspectiva de cultivo de mamona no Mato Grosso, Rangel et al. (2003) sugerem o cultivo de forma mecanizada em segunda safra. Somente no estado do Mato Grosso são aproximadamente 5 milhões de hectares semeados com soja na safra que não são utilizados para o cultivo de milho de segunda safra, algodão adensado ou feijão de segunda safra (CONAB, 2015a).

A mecanização da cultura da mamona, porém, necessita de materiais genéticos de porte baixo, que possibilitem os tratos culturais e a colheita mecanizada. Recentemente, durante o VI Congresso Brasileiro de Mamona em agosto de 2014, houve o lançamento da primeira plataforma própria para colheita de mamona da Jorge Máquinas de RondonópolisMT. Os desenvolvedores descreveram a necessidade de utilização de híbridos de porte baixo, tanto que para realizar os testes foi necessário importar híbridos de Israel.

A superioridade dos híbridos é explicada pela heterose, também conhecida como vigor híbrido, já constatada em mamona (HOOKS et al., 1971; MANIVEL et al., 1999). Estes materiais possuem maior uniformidade, ciclo precoce, resposta aos insumos agrícolas e porte baixo, permitindo a colheita mecanizada (SAVY FILHO, 1999). Já na década de 50, na Califórnia, o híbrido comercial Pacific Hybrid 6 apresentou produtividade de grãos superior às cultivares mais produtivas (ZIMMERMAN, 1958).

O manejo da fertilidade do solo por meio do uso eficiente de corretivos e fertilizantes é responsável, dentre os diversos fatores de produção, por cerca de $50 \%$ dos aumentos de produtividade das culturas (LOPES; GUILHERME, 2007). Por ser uma planta rústica que cresce espontaneamente em todo o país, a mamona frequentemente é cultivada com pouca ou nenhuma adubação. Esse fato ocorre principalmente no Nordeste, onde muitos produtores utilizam suas próprias "cultivares", culminando nas baixas produtividades. Porém, a mamona apresenta consideráveis incrementos em produtividade com a utilização de fertilizantes (SEVERINO et al., 2006; SEVERINO et al., 2005; DINIZ NETO et al., 2009a).

O nitrogênio é o nutriente de maior influência na produtividade (SEVERINO et al., 2006). A mesma resposta pode ser observada em ensaios utilizando vasos bem como ensaios com solução nutritiva (LAVRES JUNIOR et al., 2005), onde é observado menor crescimento quando a mamona é cultivada em ausência de nitrogênio. $O$ fósforo também influencia a mamona, aumentando a sua produtividade (OLIVEIRA et al., 2010), apresentando interação com o nitrogênio (SILVA et al, 2012) e é considerado o segundo nutriente de maior importância (SEVERINO et al., 2006). De acordo com o mesmo autor, o potássio é o nutriente de menor apresenta menor influência sobre a produtividade da mamona (SEVERINO et al., 2006).

Baseado na pressuposição de que híbridos seriam mais responsivos à adubação, resultando em maior produtividade do que as cultivares, o objetivo do trabalho foi avaliar o desempenho agronômico de genótipos de mamona em diferentes níveis de adubação NPK. 


\section{MATERIAL E MÉTODOS}

O experimento foi conduzido na Fazenda Experimental Lageado, Faculdade de

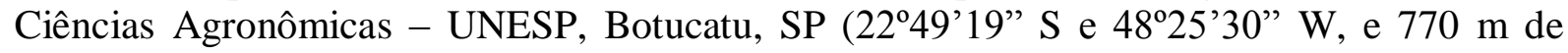
altitude), no período de outubro de 2010 a abril de 2011, em um Nitossolo Vermelho de textura argilosa. Segundo a classificação climática de Köppen, o clima da região é do tipo Cwa, caracterizado pelo clima tropical de altitude, com inverno seco e verão quente e chuvoso. As precipitações pluviais e temperaturas registradas, durante a condução do experimento são apresentadas na Figura 1. A precipitação acumulada foi de aproximadamente $1600 \mathrm{~mm}$.

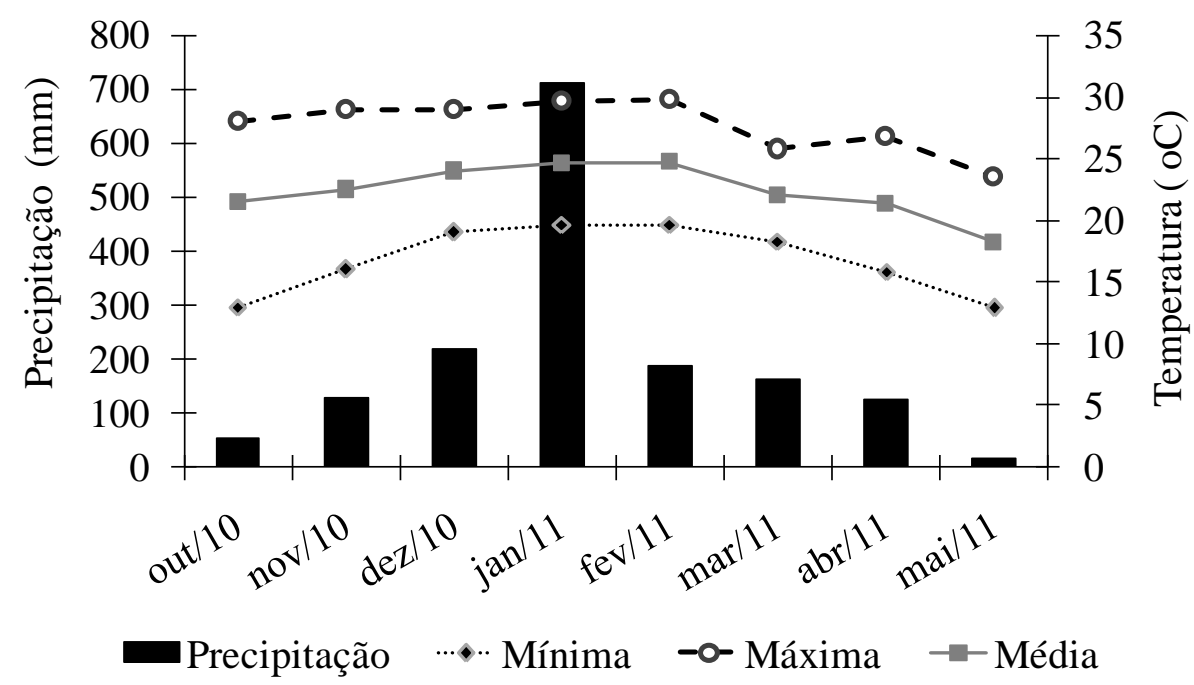

Figura 1. Valores de pluviosidade e temperatura obtidas na área experimental durante o período de outubro de 2010 a maio de 2011. Fonte: Estação Meteorológica da Fazenda Experimental Lageado - Departamento de Recursos Naturais.

As características químicas do solo (0,0-0,2 m) foram determinadas antes da instalação do experimento, obtendo os seguintes resultados: $27 \mathrm{~g} \mathrm{dm}^{-3}$ de matéria orgânica; 4,8 de $\mathrm{pH}$ $\left(\mathrm{CaCl}_{2}\right) ; 10 \mathrm{mg} \mathrm{dm}{ }^{-3}$ de P (resina); 4,4; 23; 10 e $53 \mathrm{mmol}_{\mathrm{c}} \mathrm{dm}^{-3}$ de $\mathrm{K}, \mathrm{Ca}, \mathrm{Mg}$ e H+Al, respectivamente; e $42 \%$ de saturação por bases. Com base na análise do solo e segundo recomendação de Savy Filho (2005), foi definida a dose padrão de 60-60-20 kg ha ${ }^{-1}$ de N$\mathrm{P}_{2} \mathrm{O}_{5}-\mathrm{K}_{2} \mathrm{O}$. O P e o $\mathrm{K}$ foram aplicados manualmente na semeadura e o $\mathrm{N}$ foi parcelado, aplicando $25 \%$ na semeadura e $75 \%$ em cobertura.

O delineamento experimental utilizado foi de blocos ao acaso, em esquema fatorial $4 \times 4$, com quatro repetições. O primeiro fator foi constituído por quatro genótipos [dois híbridos provenientes do Programa de Melhoramento de Mamona da UNESP-FCA (Híbrido A e Híbrido B) e duas cultivares (FCA-PB proveniente do Programa de Melhoramento de Mamona da UNESP-FCA e a cultivar comercial IAC 2028)] e o segundo fator por quatro níveis de adubação $(0,50,100$ e $150 \%$ da dose recomendada com base na análise de solo). As duas cultivares também foram desenvolvidas para serem de porte baixo.

Cada unidade experimental foi formada por cinco linhas de 4,25 m de comprimento espaçadas em $0,75 \mathrm{~m}$ e as plantas espaçadas em $0,53 \mathrm{~m}$, correspondendo a uma população de 25 mil plantas $\mathrm{ha}^{-1} \mathrm{e}$ abrangendo uma área de $15,95 \mathrm{~m}^{2}$. A parcela útil foi formada pelas três linhas centrais, descontando-se $0,53 \mathrm{~m}$ de cada extremidade. 
A semeadura foi realizada no dia 28 de outubro de 2010 utilizando três sementes por cova e aos 12 dias após a emergência (DAE) foi realizado o raleio, deixando uma planta por cova. A colheita ocorreu nos dias 10 de março de 2011 e 12 de abril de 2011.

Foram realizadas as seguintes avaliações: altura total de plantas, altura de inserção do racemo primário, número de nós, diâmetro de colmo, número de racemos por planta, número de grãos por planta, massa de grãos por planta, massa de cem grãos, comprimento total dos racemos, comprimento efetivo dos racemos (seção em que existem frutos), percentagem efetiva dos racemos, produtividade de grãos (13\% de umidade), teor e produtividade de óleo.

Os dados foram submetidos à análise de variância pelo teste $\mathrm{F}$ a $5 \%$ de probabilidade $\mathrm{e}$ as médias comparadas pelo teste de Tukey a 5\% de probabilidade.

\section{RESULTADOS E DISCUSSÃO}

Não houve interação entre genótipos e níveis de adubação para nenhuma das variáveis analisadas. Para todas as variáveis biométricas, os híbridos apresentaram menores valores do que as cultivares (Tabela 1). A cultivar FCA-PB apresentou resultados intermediários para todas as variáveis biométricas, com exceção de altura total de plantas (Tabela 1). Lopes et al. (2008) em ensaio de crescimento inicial de genótipos de mamona, observaram maior crescimento em altura da cultivar BRS Nordestina em relação aos híbridos Lyra e Savana.

Tabela 1. Altura total de plantas (AP), altura de inserção do racemo primário (AIRP), número de nós até a inserção do racemo primário $(\mathrm{NN})$, comprimento médio do internódio (CI) e diâmetro de colmo (DC) dos genótipos de mamona cultivados em diferentes níveis de adubação NPK. Botucatu-SP, 2010-2011.

\begin{tabular}{|c|c|c|c|c|}
\hline Genótipos & $\mathrm{AP}$ & AIRP & NN & $\mathrm{DC}$ \\
\hline & $(\mathrm{cm})$ & $(\mathrm{cm})$ & - & $(\mathrm{mm})$ \\
\hline Híbrido A & $69,8 \mathrm{~b}$ & $22,8 \mathrm{c}$ & $9,0 \mathrm{c}$ & $14,1 \mathrm{c}$ \\
\hline Híbrido B & $73,4 \mathrm{~b}$ & $22,5 \mathrm{c}$ & $9,8 \mathrm{c}$ & $14,4 \mathrm{c}$ \\
\hline FCA-PB & 96,9 a & $30,4 \mathrm{~b}$ & $11,4 \mathrm{~b}$ & $18,1 \mathrm{~b}$ \\
\hline IAC 2028 & $130,2 \mathrm{a}$ & 47,6 a & $16,2 \mathrm{a}$ & $23,4 \mathrm{a}$ \\
\hline \multicolumn{5}{|c|}{ Quadrado médio } \\
\hline Genótipos (G) & $12376,9 * *$ & $2205,3 * *$ & $164,7 * *$ & $304,0 * *$ \\
\hline Níveis de adubação (N) & $1429,7 * *$ & $16,0^{\mathrm{ns}}$ & $7,3^{*}$ & $33,9 * *$ \\
\hline $\mathrm{G} \times \mathrm{N}$ & $389,5^{\mathrm{ns}}$ & $7,8^{\mathrm{ns}}$ & $1,4^{\mathrm{ns}}$ & $4,4^{\mathrm{ns}}$ \\
\hline $\mathrm{CV}(\%)$ & 19,2 & 13,9 & 13,4 & 9,2 \\
\hline
\end{tabular}

Ferreira et al. (2009) encontraram maior altura de plantas e altura de inserção do racemo primário das cultivares BRS Nordestina e BRS Paraguaçu em relação aos híbridos Lyra e Savana. O crescimento vegetativo reduzido apresentado pelos híbridos é um dos objetivos mais importantes nos programas de melhoramento, visando à obtenção de materiais com menor dreno vegetativo e com características que possibilitem seu adensamento e favoreçam a colheita mecanizada. A precocidade é um dos objetivos do melhoramento e tem estreita relação com a altura de inserção do racemo primário, que é dependente do número de nós até a inserção do racemo primário. Desta forma, os híbridos selecionados para porte baixo e precocidade, apresentam menor altura de inserção bem como menor número de nós (Tabela 1). Cargnelutti Filho et al. (2010) encontraram valores de altura de inserção do racemo 
primário para os híbridos Sara e Lyra de 26,6 e 25,9 cm, respectivamente, sendo semelhantes aos híbridos do Programa de Melhoramento da UNESP.

Para diâmetro de colmo observou-se superioridade das cultivares em relação aos híbridos (Tabela 1), corroborando os resultados reportados por Lopes et al. (2008) e Ferreira et al. (2009).

Em relação aos níveis de adubação houve efeito linear crescente da altura total e do diâmetro de colmo com o aumento da adubação (Figura 2a e 2c). O aumento de variáveis biométricas em função do aumento da adubação NPK foi também observado por Diniz Neto et al. (2009b). Com doses de 0, 50, 100 e 150\% do nível base 80-50-30, os autores encontraram ajuste linear crescente para altura de plantas e diâmetro caulinar da cultivar Mirante sob cultivo irrigado.

A altura de inserção do racemo primário não foi influenciada pelo aumento dos níveis de adubação (Figura 2a). Esse resultado não corrobora os observados por Severino et al. (2006) e Severino et al. (2005). Ambos os trabalhos observaram maior altura de inserção quando foi aplicada a dose de adubo recomendada pela análise de solo, em comparação com a testemunha. A ausência de resposta da altura de inserção pode ser explicada pela redução do número de nós até a inserção do racemo primário (Figura 2b). Provavelmente houve aumento do comprimento de internódio, como observado por Severino et al. (2006).

O caule primário cresce e emite novas folhas e nós até que ocorra a emissão do racemo primário, iniciando a fase reprodutiva. Os fatores ambientais que mais determinam o início da fase reprodutiva nas plantas são o fotoperíodo e o acúmulo de graus-dia. Desta forma, esperase que haja pouca ou nenhuma influência da adubação no número de nós. Severino et al. (2006) e Severino et al. (2005) observaram ausência de resposta à adubação no número de nós até a inserção do racemo primário.

O híbrido B e a cultivar FCA-PB apresentaram mais racemos do que a cultivar IAC 2028, que apresentou apenas 2,8 racemos (Tabela 2). A menor emissão de racemos do cultivar IAC-2028 pode estar relacionada ao seu ciclo longo, pois este material emite o racemo primário em torno de $60 \mathrm{DAE}$, enquanto os híbridos emitem entre 30-35 DAE e a cultivar FCA-PB em torno de 35-40 DAE. A emissão dos racemos de ordem superior também apresenta o mesmo comportamento. Ferreira et al. (2009) observaram maior número de racemos nos híbridos Lyra e Savana, média de 2 por planta, enquanto as cultivares BRS Nordestina e BRS Paraguaçu apresentaram média de 1,6 racemos por planta.

Os híbridos e a cultivar FCA-PB apresentaram menor número de grãos por racemo em relação a cultivar IAC-2028, sendo resultado do maior número de racemos. Esse fato ocorreu devido ao maior número de drenos presentes nos híbridos e na cultivar FCA-PB, resultando em menor número de grãos por racemo e consequentemente afetando a massa de grãos por racemo (Tabela 2). Dados divergentes foram observados por Ferreira et al. (2009), que obtiveram maior massa de grãos por racemos nos híbridos (Lyra e Savana) do que nas cultivares (BRS Nordestina e BRS Paraguaçu). Porém, esse comportamento pode ser explicado pelo ciclo mais longo das cultivares, uma vez que as precipitações observadas no experimento concentraram-se apenas nos dois primeiros meses de cultivo, prejudicando as cultivares BRS Nordestina e BRS Paraguaçu.

Com relação à massa de cem grãos, a cultivar IAC 2028 foi superior aos demais genótipos (Tabela 2). Esses resultados corroboram os encontrados por Ferreira et al. (2009), onde a massa de cem grãos das cultivares BRS Nordestina e BRS Paraguaçu foi superior ao dos híbridos Lyra e Savana. 

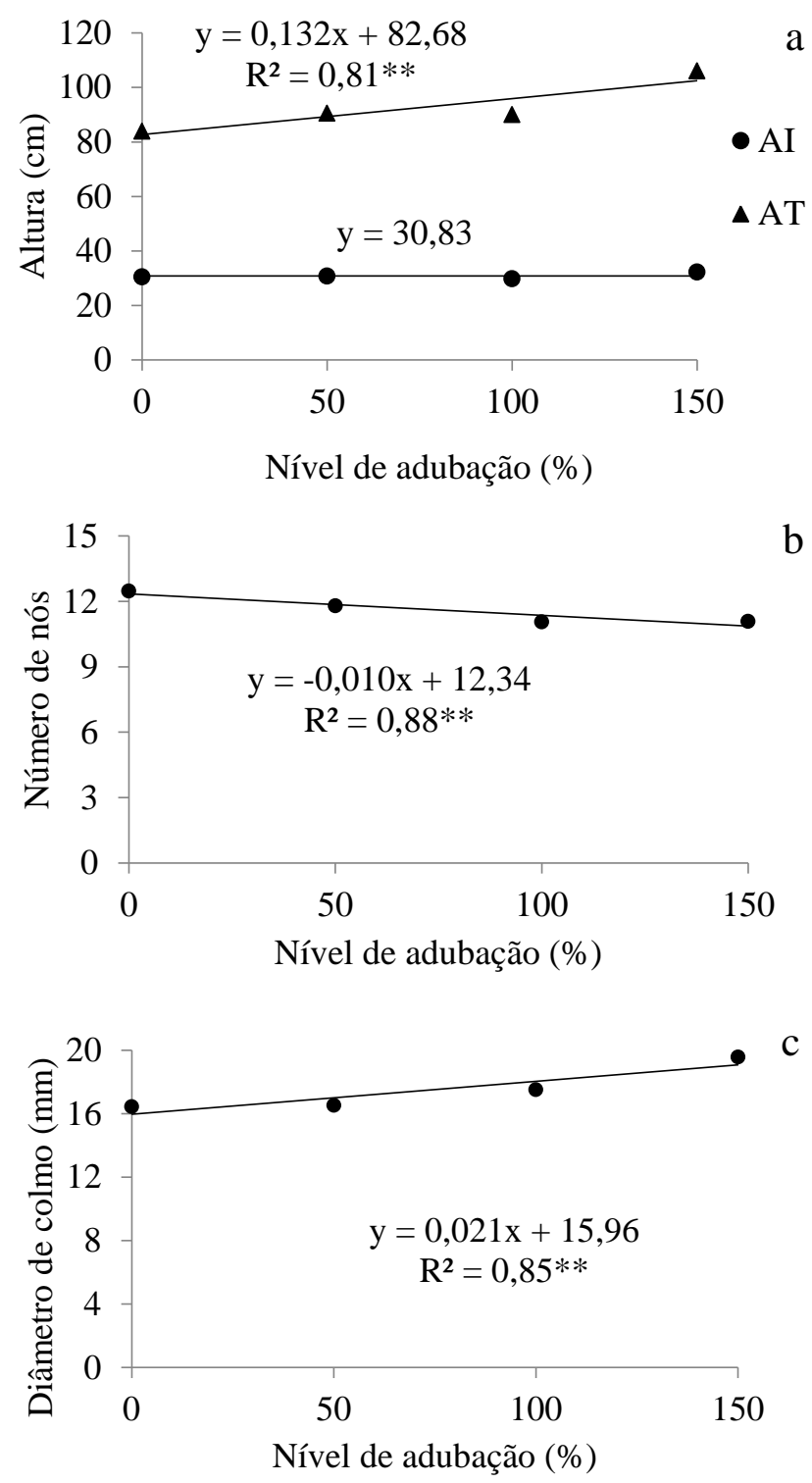

Figura 2. Altura total de plantas e altura de inserção do racemo primário (a), número de nós (b) e diâmetro de colmo (c) dos genótipos de mamona em diferentes níveis de adubação NPK.

Observa-se que a cultivar IAC 2028 foi superior aos demais genótipos (Tabela 2). A superioridade da cultivar IAC 2028 pode estar associada aos racemos com maior potencial produtivo (maior número de grãos por racemo e maior massa de cem grãos). $\mathrm{O}$ número de racemos por planta é considerado o componente de produção mais importante na mamona, porém, vale destacar que os híbridos utilizados são experimentais e a cultivar IAC 2028 foi desenvolvida para o estado de São Paulo, apresentando melhor adaptação no ambiente estudado. Esses resultados divergem dos encontrados por Ferreira et al. (2009). Os autores observaram $42 \%$ de superioridade dos híbridos Lyra e Savana em relação às cultivares BRS Nordestina e BRS Paraguaçu.

Os níveis de adubação influenciaram todos os componentes de produção e, consequentemente, a produtividade. Todas variáveis apresentaram efeito linear positivo (Figura 3). Diniz Neto et al. (2009b) observaram aumento do número de racemos com aumento da adubação NPK e do número de frutos por racemo no tratamento irrigado. Porém, os mesmos autores, em publicação paralela, mas referente ao mesmo experimento, não 
observaram variação na massa de cem grãos em função do aumento da adubação NPK para nenhum dos dois locais, nenhuma das duas cultivares, tanto no plantio em sequeiro como no plantio irrigado (DINIZ NETO et al., 2009a). Segundo Sadras e Slafer (2012), os componentes de produção que são determinados mais tardiamente durante o ciclo possuem menor plasticidade. Desta forma espera-se que haja menos variação na massa de cem grãos, como observado pela menor inclinação da reta no presente trabalho (Figura 3c).

Tabela 2. Número de racemos por planta (NR), número de grãos por racemo (NGR), massa de grãos por racemo (MGR), massa de cem grãos (MCG). Botucatu-SP, 2010

\begin{tabular}{lcccc}
\hline Genótipos & NR & NGR & MCG & PROD \\
\hline & - & - & $(\mathrm{g})$ & $\left(\mathrm{kg} \mathrm{ha}^{-1}\right)$ \\
Híbrido A & $3,5 \mathrm{ab}$ & $60,2 \mathrm{~b}$ & $25,0 \mathrm{c}$ & $1308,9 \mathrm{~b}$ \\
Híbrido B & $3,7 \mathrm{a}$ & $51,8 \mathrm{~b}$ & $27,2 \mathrm{~b}$ & $1303,4 \mathrm{~b}$ \\
FCA-PB & $4,0 \mathrm{a}$ & $52,4 \mathrm{~b}$ & $28,5 \mathrm{~b}$ & $1505,0 \mathrm{~b}$ \\
IAC 2028 & $2,8 \mathrm{~b}$ & $84,6 \mathrm{a}$ & $32,7 \mathrm{a}$ & $1970,2 \mathrm{a}$ \\
\hline \multicolumn{5}{c}{ Quadrado médio } \\
\hline Genótipos (G) & $3,8^{* *}$ & $3771,0^{* *}$ & $168,3^{* *}$ & $1569714,8^{* *}$ \\
Níveis de adubação (N) & $2,2^{*}$ & $1384,3^{* *}$ & $18,8^{*}$ & $2626607.9^{* *}$ \\
G x N & $0,3^{\text {ns }}$ & $238,5^{\text {ns }}$ & $5,7^{\text {ns }}$ & $166366,0^{\text {ns }}$ \\
CV $(\%)$ & 20,8 & 23,5 & 7,8 & 25,3 \\
\hline
\end{tabular}

Médias seguidas de mesma letra na coluna não diferem entre si pelo teste de Tukey a $5 \%$ de probabilidade. ${ }^{* *},{ }^{*},{ }^{\text {ns }}$ : significativo a $1 \%, 5 \%$ e não significativo pelo teste $\mathrm{F}$, respectivamente.

Observou-se efeito linear positivo para produtividade, ou seja, houve resposta acima da dose recomendada com base na análise de solo (Figura 3d). Severino et al. (2006b) utilizando a cultivar BRS Nordestina encontraram aumento de $114 \%$ na produtividade do tratamento com adubação referencial $\left(50,60\right.$ e $40 \mathrm{~kg} \mathrm{ha}^{-1}$ de $\mathrm{N}, \mathrm{P}$ e K, respectivamente) em relação à testemunha. Os autores não observaram aumento de produtividade quando elevaram a dose dos nutrientes de forma isolada, acima da dose referencial. Diniz Neto et al. (2009a) observaram respostas variadas para produtividade de grãos, sendo que somente em alguns casos a adubação com 100\% da dose de referência (80-50-30 de N, P e K, respectivamente) superou a testemunha. Porém, na maioria dos casos o tratamento de $150 \%$ da adubação de referência promoveu aumento de produtividade em relação à testemunha.

De modo geral, observaram-se indicações de que a cultura da mamona possa ser cultivada com níveis mais altos de adubação. Simulando o aumento dos custos, foram pesquisados os preços em empresa de adubos na cidade de Sorriso no dia 07/05/15, sendo de 1325,1472 e 1020 reais por tonelada de ureia, cloreto de potássio e superfosfato simples, respectivamente. $\mathrm{O}$ aumento do custo com o incremento de $50 \%$ na adubação da dose recomendada (60-60-20 kg ha ${ }^{-1}$ de $\mathrm{N}-\mathrm{P}_{2} \mathrm{O}_{5}-\mathrm{K}_{2} \mathrm{O}$ ) seria $\mathrm{R} \$ 282,99$ ha $^{-1}$. A cotação da mamona em baga paga ao produtor estava em média $\mathrm{R} \$ 70,60$ a saca de $60 \mathrm{~kg}$ em abril de 2015 , com um preço mínimo estabelecido de R \$ 63,47 (CONAB, 2015b).

Desta forma, o aumento da adubação promoveu incremento de 5,2 sacas por hectare (312 $\mathrm{kg} \mathrm{ha}^{-1}$ ), ou seja, um acréscimo de $\mathrm{R} \$ 367,12$ levando em consideração o preço de mercado e acréscimo de $\mathrm{R} \$ 330,04$ de acordo com o preço mínimo. Descontando o custo com o fertilizante, ainda sobrariam $\mathrm{R} \$ 84,13 \mathrm{ha}^{-1}$ e $\mathrm{R} \$ 47,05 \mathrm{ha}^{-1}$, para venda de mercado e preço mínimo, respectivamente.

Novos estudos devem ser conduzidos visando elucidar aspectos da adubação em solos da região do Cerrado, local que promete ser a nova fronteira para a cultura da mamona. 

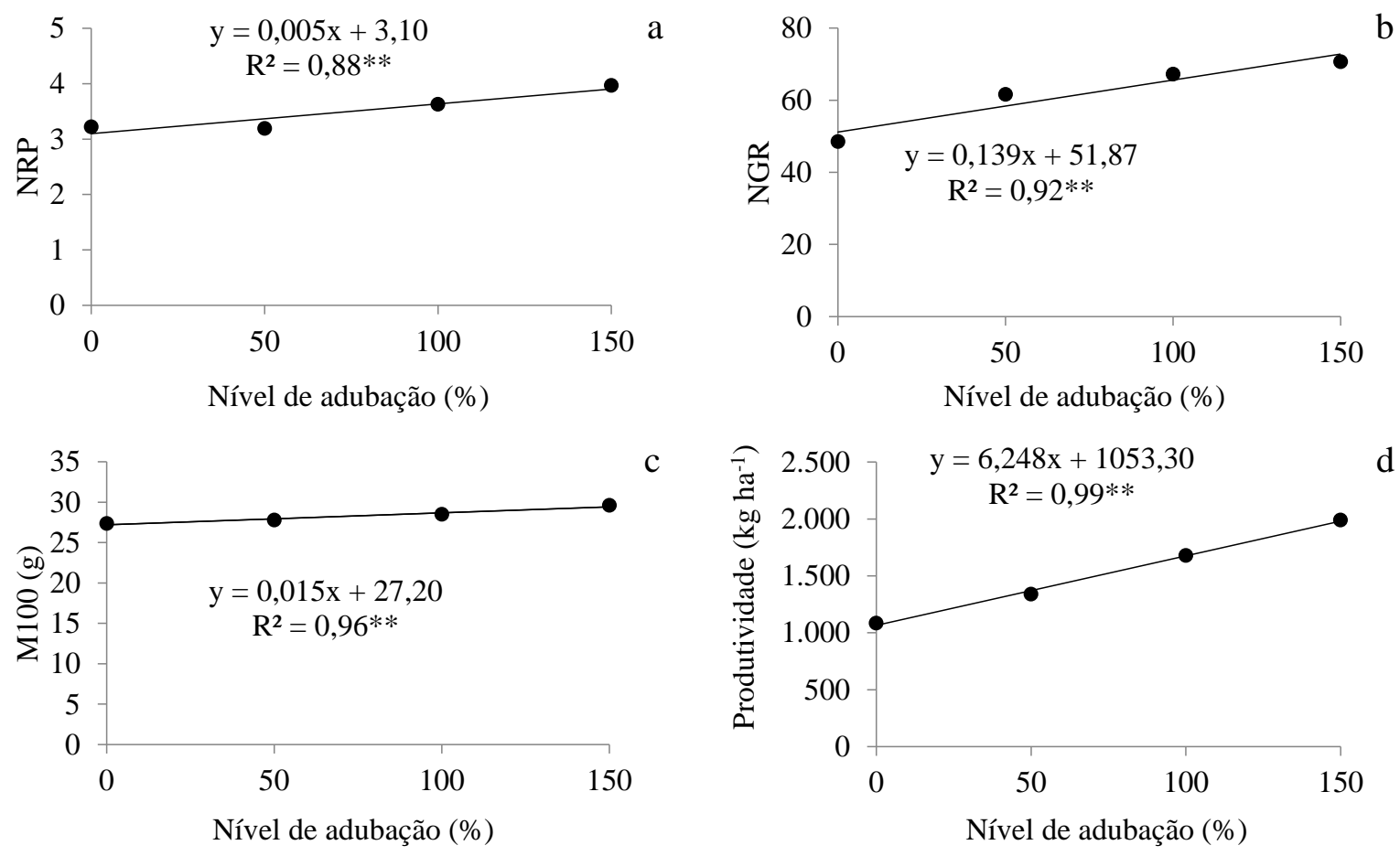

Figura 3. Número de racemos por planta (NRP) (a), número de grãos por racemo (NGR) (b), massa de 100 grãos (M100) (c) e produtividade de grãos (d) dos genótipos de mamona em diferentes níveis de adubação NPK.

\section{CONCLUSÕES}

Os híbridos de mamona apresentam porte de planta inferior às cultivares, o que favorece a colheita mecanizada.

A cultivar apresentou maior produtividade de grãos do que os genótipos, principalmente devido ao maior potencial de produção dos racemos.

O aumento da adubação até doses superiores das recomendadas pela literatura promove aumento da produtividade.

\section{REFERÊNCIAS BIBLIOGRÁFICAS}

CARGNELUTTI FILHO, A.; LOPES, S. J.; BRUM, B.; SILVEIRA, T. R.; TOEBE, M.; STORCK, L. Tamanho de amostra de caracteres em híbridos de mamoneira. Ciência Rural, Santa Maria-RS, v. 40, n. 2, p. 280-287, 2010.

CHIERICE, G. O.; CLARO NETO, S. Aplicação Industrial do Óleo. In: AZEVEDO, D. M. P.; BELTRÃO, N. E. M. (Ed.). O agronegócio da mamona no Brasil. 2. ed. Campina Grande-RN: Embrapa Algodão; Brasília-DF: Embrapa Informação Tecnológica, 2007. p. $417-$ 448.

CONAB. COMPANHIA NACIONAL DE ABASTECIMENTO. Acompanhamento da Safra Brasileira: Grãos. Oitavo Levantamento. Maio de 2015. Disponível em: < http://www.conab.gov.br/OlalaCMS/uploads/arquivos/15_05_13_08_46_55_boletim_graos_ maio_2015.pdf>. Data de acesso: 15 maio 2015a. 
CONAB. COMPANHIA NACIONAL DE ABASTECIMENTO. Conjuntura mensal: Mamona. Abril 2015. Disponível em: <http://www.conab.gov.br/OlalaCMS/uploads/arquivos/15_05_11_17_06_26_mamonaabril2 015.pdf > . Data de acesso: 15 de abril de 2015b.

DINIZ NETO, M. A.; TÁVORA, F. J. A. F.; CRISÓSTOMO, L. A.; DINIZ, B. L. M. T. Adubação NPK e épocas de plantio para mamoneira. I - Componentes da produção e produtividade. Revista Ciência Agronômica, Fortaleza-CE, v. 40, n. 4, p. 578-587, 2009a.

DINIZ NETO, M. A.; TÁVORA, F. J. A. F.; CRISÓSTOMO, L. A.; DINIZ, B. L. M. T. Adubação NPK e épocas de plantio para mamoneira. II - Componentes das fases vegetativas e reprodutivas. Revista Ciência Agronômica, Fortaleza-CE, v. 40, n. 3, p. 417-426, 2009b.

FAO. FOOD AND AGRICULTURE ORGANIZATION OF THE UNITED NATIONS. Top production: Castor oil seed. Disponível em: 〈http://faostat.fao.org/site/339/default.aspx >. Data de acesso: 14 de fevereiro de 2014.

FERREIRA, M. G. C.; MARUYAMA, W. I; SORATTO, R. P. Avaliação de cultivares de mamona em dois arranjos de plantas no outono-inverno em Cassilândia-MS. Revista Brasileira de Oleaginosas e Fibrosas, Campina Grande-RN, v. 13, n. 2, p. 53-60, 2009.

HOOKS, J. A.; WILLIAMS, J. H.; GARDNER, C. O. Estimates of heterosis from a diallel cross of inbred lines of castors, Ricinus communis L. Crop Science, Madison, v. 11, n.1, p. 651-655, 1971.

LOPES, A. S.; GUILHERME, L. R. G. Fertilidade do solo e produtividade agrícola. In: NOVAIS, R. F. et al. (Eds.). Fertilidade do solo. Viçosa-MG: Sociedade Brasileira de Ciência do Solo, 2007. p. 1-64.

LOPES, F. F. M.; BELTRÃO, N. E. M.; LOPES NETO, J. P.; PEDROZA, J. P. Crescimento inicial de genótipos de mamoneira com sementes submetidas ao envelhecimento acelerado. Revista Brasileira de Oleaginosas e Fibrosas, Campina Grande-RN, v. 12, p. 69-79, 2008.

MANIVEL, P. et al. Heterosis for yield and its components over environments in castor (Ricinus communis L.). The Madras Agricultural Journal, Tindivanam, v. 86, n. 1-3, p. 6568, 1999.

OLIVEIRA, J. P.M.; SCIVITTARO, W. B.; CASTILHOS, R. M. V; OLILVEIRA FILHO, LCI. Adubação fosfatada para cultivares de mamoneira no Rio Grande do Sul. Ciência Rural, Santa Maria-RS, v. 40, n. 8, p. 1835-1839, 2010.

RANGEL, L. E. P.; FERREIRA, L. G.; ALMEIDA, V. M.; MENEZES, V. L. Mamona: Situação Atual e Perspectivas no Mato Grosso. Campina Grande-RN: Embrapa Algodão, 2003. 20p. (Embrapa Algodão. Documentos, 106).

SADRAS, V. O.; G. A. SLAFER. Environmental modulation of yield components in cereals: Heritabilities reveal a hierarchy of phenotypic plasticities. Field Crops Research, Germany, v. 127, p. 215-224, 2012.

SAVY FILHO, A. Hibridação em mamoma. In: BORÉM, A. (Ed.). Hibridação Artificial de Plantas. Viçosa-MG: UFV, 1999. p. 321-342

SAVY FILHO, A. Mamona: tecnologia agrícola. Campinas-SP: Emopi, 2005. 105 p.

SEVERINO, L. S.; MORAES, C. R. A.; FERREIRA, G. B.; CARDOSO, G. D.; GONDIM, T. M. S.; BELTRÃO, N. E. M.; VIRIATO, J. R. Crescimento e produtividade da mamoneira sob fertilização química em região semi-árida. Campina Grande-RN: Embrapa Algodão, 2005. 20 p. (Boletim de Pesquisa e Desenvolvimento 62) 
SEVERINO, L. S.; FERREIRA, G. B.; MORAES, C. R. A.; GONDIM, T. M. S.; FREIRE, W. S. A.; CASTRO, D. A.; CARDOSO, G. D.; BELTRÃO, N. E. M. Crescimento e produtividade da mamoneira adubada com macronutrientes e micronutrientes. Pesquisa Agropecuária Brasileira, Brasília-DF, v. 41, n. 4, p. 563-568, 2006.

SILVA, A. R. C.; OLIVEIRA, F. H. T.; ARAÚJO, A. P.; MEDEIROS, J. F.; ZONTA, E. Doses de nitrogênio e fósforo para a produção econômica da mamoneira no município de Mossoró-RN. Revista Caatinga, Mossoró-RN, v. 25, n. 4, p. 52-60, 2012.

ZIMMERMAN, L. H. Castor beans: a new oil crop for mechanized production. Advances in Agronomy, San Diego, n. 10, p. 257-288, 1958. 